\title{
Orthostatic hypotension and anti-hypertensive therapy in the elderly
}

\author{
M.D. Fotherby and J.F. Potter \\ University Department of Medicine and Therapeutics, Division of Medicine for the Elderly, Glenfield \\ General Hospital, Groby Road, Leicester LE3 9QP, UK
}

\begin{abstract}
Summary: The effect of withdrawing or continuing anti-hypertensive therapy on orthostatic blood pressure change in elderly hypertensive subjects was examined. Subjects meeting criteria for therapy withdrawal had supine and standing blood pressure measurements taken on treatment, and at 1,3,6,9 and 12 months off treatment whilst receiving standard non-pharmacological advice to lower blood pressure. Subjects not meeting blood pressure criteria for treatment withdrawal or were unwilling to stop treatment had blood pressure measurements taken after 6 and 12 months whilst also receiving non-pharmacological advice. Orthostatic hypotension was defined as a mean systolic blood pressure fall $\geqslant 20 \mathrm{mmHg}$ on standing from a supine position.

Forty-seven subjects (median age 76 years, range 65-84 years) had treatment withdrawn. Thirteen subjects (median age 73 years, range 68-82 years) continued on their treatment. Twelve months after treatment withdrawal there was a significant reduction in the number demonstrating orthostatic hypotension from $11(23 \%)$ to four $(11 \%)(P<0.05)$, whilst the group continuing on treatment showed no change. In the withdrawal group those with orthostatic hypotension on treatment $(n=11)$ were older $(79$ versus 74 years, $P=0.05$ ), had higher prewithdrawal systolic blood pressure (164 \pm 21 versus $147 \pm 17 \mathrm{mmHg}, P=0.02)$ compared to those without, although there was no difference in body mass index, gender, number or type of anti-hypertensive drugs taken. In elderly hypertensive subjects withdrawal of anti-hypertensive therapy and institution of non-pharmacological treatment can over several months reduce the prevalence of orthostatic hypotension.
\end{abstract}

\section{Introduction}

It is often assumed that the prevalence of orthostatic hypotension in the elderly is increased by the use of anti-hypertensive agents, ${ }^{1-5}$ although there are reports suggesting such treatment has little effect on orthostatic blood pressure control. ${ }^{6-14}$ The aims of this study were to assess prospectively the effect of continuing or withdrawing antihypertensive therapy on postural blood pressure control in a group of elderly hypertensive subjects during a one year follow-up period.

\section{Methods}

\section{Subjects}

Subjects $\geqslant 65$ years with blood pressure $<175 /$ $100 \mathrm{mmHg}$ who had been on pharmacological treatment for $>$ one year and were currently attending a hospital-based hypertension clinic were

Correspondence: M.D. Fotherby, B.Sc., M.R.C.P. Accepted: 23 June 1994 asked to participate in a study of treatment withdrawal. All subjects were ambulant and lived at home; those with myocardial infarction or stroke within the preceding 6 months, having angina or known major illnesses were excluded. Also excluded were subjects with diabetes and other diseases known to affect blood pressure, such as Parkinson's disease, or on medication other than anti-hypertensives known to affect blood pressure.

\section{Methods}

After 10 minutes supine rest, the mean of three supine and three standing blood pressure measurements, taken 1-3 minutes after standing, were recorded by the same investigator and repeated at three further clinic visits. The mean of the blood pressure measurements on the third visit was taken as the blood pressure level on treatment. All measurements were recorded at least 2 hours after a meal and 6 hours following the last medication using a standard mercury sphygmomanometer and Korotkoff phase $\mathrm{V}$ for diastolic blood pres- 
sure. In those meeting withdrawal criteria (systolic blood pressure $\leqslant 175 \mathrm{mmHg}$ and/or diastolic blood pressure $\leqslant 100 \mathrm{mmHg}$ ), anti-hypertensive therapy was stopped and standard nonpharmacological methods for blood pressure reduction were substituted. Briefly, all subjects were given verbal advice by the physician to reduce their sodium intake by not adding salt at the table and to reduce that used in cooking; to increase their consumption of fruit and vegetables and take a minimum of 30 minutes aerobic exercise daily. Overweight subjects (body mass index $>26 \mathrm{~kg} / \mathrm{m}^{2}$ ) were given advice by the physician and dietician to lose weight.

Following treatment withdrawal, subjects whose systolic blood pressure was $\geqslant 175 \mathrm{mmHg}$ and/or whose diastolic blood pressure was $>100 \mathrm{mmHg}$ on two occasions were withdrawn from the study. Those subjects unsuitable for anti-hypertensive treatment withdrawal because of mean blood pressure being greater than the set criteria or unwilling to stop therapy, continued on their pharmacological treatment in addition to receiving non-pharmacological advice. Blood pressure measurements were recorded at a similar time of day by the same investigator after 1, 3, 6, 9 and 12 months off anti-hypertensive therapy. Those continuing on anti-hypertensive therapy had repeat supine and standing blood pressures recorded at 6 and 12 months. At the time of blood pressure recordings, the investigator was unaware of the treatment status of the subjects. Orthostatic hypotension was defined as a mean systolic blood pressure fall $\geqslant 20 \mathrm{mmHg}$ on standing from a supine position. The study was approved by the local ethical committee.
Between group comparisons for normally distributed continuous data (presented as mean \pm s.d.) were analysed using the two-sample Student's $t$-test, otherwise the Mann-Whitney test was used with data presented as median value and range. Categorical data were analysed using chi-squared and Fisher's exact test.

\section{Results}

A total of 47 subjects, 28 female (median age 76 years, range 65-84 years) met the criteria for drug withdrawal and were followed up for 12 months. Prior to withdrawal, $62 \%$ received thiazide diuretics, $47 \%$ calcium antagonists and $43 \%$ betaadrenoceptor antagonists. Of the 13 subjects remaining on treatment (median age 73 years, range 68-82 years), 11 did not meet criteria for anti-hypertensive withdrawal and two living some considerable distance from the hospital did not want to attend the more frequent follow-up required of the withdrawal group. However, all 13 subjects agreed to follow-up blood pressure measurements on their original treatment; $58 \%$ received thiazide diuretics, $45 \%$ calcium antagonists and $38 \%$ beta-adrenoceptor antagonists.

The mean supine blood pressure and number of patients with orthostatic hypotension at each visit are shown in Table I. For the withdrawal group, the number of subjects having orthostatic hypotension fell significantly from $11(23 \%)$ on antihypertensive treatment to four $(11 \%)(P<0.05)$ by 12 months off treatment. In contrast, the group continuing anti-hypertensive therapy showed no

Table I Blood pressure levels ( \pm s.d.) and number of subjects (\%) showing orthostatic systolic blood pressure fall $\geqslant 20 \mathrm{mmHg}$ in subjects withdrawn from anti-hypertensive therapy, including those with orthostatic hypotension on and off treatment, and in subjects continuing on anti-hypertensive therapy for 12 months

\begin{tabular}{llcccccc}
\hline & & & \multicolumn{4}{c}{ Months off treatment } \\
& & On treatment & 1 & 3 & 6 & 9 & 12 \\
\hline Whole & SBP & $151 \pm 19$ & $173 \pm 19$ & $169 \pm 21$ & $167 \pm 16$ & $163 \pm 15$ & $164 \pm 13 *$ \\
group & DBP & $81 \pm 11$ & $92 \pm 10$ & $91 \pm 12$ & $90 \pm 11$ & $84 \pm 15$ & $86 \pm 11$ \\
$(n=47)$ & OH (\%) & $11(23 \%)$ & $8(17 \%)$ & $7(15 \%)$ & $4(9 \%)$ & $5(11 \%)$ & $4(9 \%)^{*}$ \\
OH on & SBP & $164 \pm 21$ & $176 \pm 23$ & $173 \pm 17$ & $169 \pm 13$ & $175 \pm 17$ & $172 \pm 15$ \\
treatment & DBP & $85 \pm 7$ & $90 \pm 8$ & $93 \pm 8$ & $89 \pm 11$ & $86 \pm 17$ & $87 \pm 14$ \\
$(n=11)$ & OH (\%) & $11(100 \%)$ & $6(55 \%)$ & $4(36 \%)$ & $3(27 \%)$ & $3(27 \%)$ & $2(18 \%)^{* *}$ \\
No OH on & SBP & $147 \pm 17$ & $172 \pm 18$ & $167 \pm 22$ & $167 \pm 17$ & $157 \pm 11$ & $159 \pm 9$ \\
treatment & DBP & $80 \pm 12$ & $93 \pm 11$ & $90 \pm 13$ & $90 \pm 12$ & $83 \pm 15$ & $85 \pm 10$ \\
$(n=36)$ & OH (\%) & $0(0 \%)$ & $2(6 \%)$ & $3(8 \%)$ & $1(3 \%)$ & $2(6 \%)$ & $2(6 \%)$ \\
Treatment & SBP & $179 \pm 26$ & & & $175 \pm 24$ & $97 \pm 10$ & $178 \pm 27$ \\
group & DBP & $97 \pm 13$ & & & $5(38 \%)$ & $99 \pm 8$ \\
$(n=13)$ & OH(\%) & $5(38 \%)$ & & & & $4(31 \%)$ \\
\hline
\end{tabular}

${ }^{*} P<0.05 ;{ }^{* *} P<0.001$ versus on treatment value. SBP $=$ systolic blood pressure; $\mathrm{DBP}=$ diastolic blood pressure; $\mathrm{OH}=$ orthostatic hypotension. 
significant change in the prevalence of orthostatic hypotension after 12 months, although there was intrasubject variability in the orthostatic blood pressure changes seen at the three different time points. The prevalence of orthostatic hypotension in the group on treatment $(38 \%)$ was not significantly greater $(P=0.23)$ than that in the withdrawal group whilst on treatment $(23 \%)$, despite supine systolic blood pressure being significantly higher $(179 \pm 26$ versus $151 \pm 19$ $\mathrm{mmHg}, P<0.01$ ).

In the withdrawal group, those with orthostatic hypotension on treatment $(n=11)$ were older (79 years, range 65-84 years versus 74 years, range 65-83 years; $P=0.05$ ) and had higher prewithdrawal systolic blood pressure $(164 \pm 21$ versus $147 \pm 17 \mathrm{mmHg}, P=0.02$ ) but not diastolic blood pressure compared to those without orthostatic hypotension. There was no difference in body mass index, gender, number or type of anti-hypertensive drugs taken between either group. As shown in Table I, over a 12-month follow-up period off treatment the number of subjects who initially had orthostatic hypotension on treatment fell significantly $(P<0.001)$, while those without orthostatic hypotension on-treatment did not show a significant increase in orthostatic hypotension over the study period. Although orthostatic blood pressure change was related to supine systolic blood pressure at baseline $(r=0.50, P<0.001)$, this was not so after 12 months off treatment. In the subjects remaining on therapy, both systolic and diastolic blood pressure were significantly higher $(P<0.05)$ than in those withdrawn from treatment, although the body mass index, gender, number and type of anti-hypertensive drugs taken were not significantly different between these groups.

\section{Discussion}

The effect of anti-hypertensive medications on orthostatic hypotension is unclear. In treated hypertensive patients such medications are often considered responsible for its presence. ${ }^{1-4}$ There are reports of a greater prevalence of orthostatic hypotension in persons taking anti-hypertensive medication compared to those not doing so. ${ }^{5}$ However, many other studies in elderly subjects have reported no significant association between the use of anti-hypertensive agents and postural change in systolic blood pressure, or have related it to the higher systolic blood pressure level in treated hypertensives compared to normotensives. ${ }^{6-10}$ Harris et al. ${ }^{11}$ found the prevalence of orthostatic hypotension in persons not taking anti-hypertensive medication to be $6.6 \%$ and for those taking medication $13 \%$, but within each blood pressure stratum the prevalence rates were similar. In the Cardiovascular Health Study, Rutan et al. ${ }^{12}$ found orthostatic hypotension to be weakly related to the use of beta-blocking and vasodilating agents, but not with diuretics, angiotensin converting enzyme inhibitors or alpha-receptor-blocking agents. Myers et $a l .{ }^{13}$ also found diuretics, taken for hypertension, cardiac failure and other disorders, to have no effect on the frequency of orthostatic hypotension in the elderly. These studies have, however, compared two separate groups of subjects differing not only with respect to use of anti-hypertensive treatment but also in respect of being either hypertensive or normotensive-a difference reflecting not only blood pressure levels but perhaps also vascular pathology and autonomic functioning ${ }^{15}$ and hence orthostatic blood pressure control. ${ }^{16}$

Whether currently used anti-hypertensive agents do increase the risk of developing or exacerbating orthostatic hypotension in elderly hypertensive persons has remained unclear. A recent study of 12 elderly patients with systolic hypertension submitted to orthostatic stress on a tilt-table before and one year after $50 \mathrm{mg}$ hydrochlorothiazide daily, found such treatment resulted in no significant hypotensive episodes. ${ }^{16}$ However, their subjects were well and without evidence of significant orthostatic hypotension off treatment.

The present study in two groups of hypertensives: suggests that anti-hypertensive therapy based mainly on low-dose thiazide diuretics, betablockers and calcium antagonists does increase the risk of developing orthostatic hypotension. Despite an increase in systolic blood pressure on withdrawal of pharmacological treatment, the prevalence of orthostatic hypotension fell in the group as a whole and also in those classified as having orthostatic hypotension whilst on treatment. There was, however, considerable variability in the orthostatic blood pressure change within subjects each time blood pressure was measured, a point previously highlighted by Lipsitz et al. ${ }^{17}$ The non-significantly higher prevalence of orthostatic hypotension in the group on treatment $(38 \%)$ compared to the withdrawal group whilst on treatment $(23 \%)$ is probably a reflection of the higher supine systolic blood pressure levels in the former group. The systolic blood pressure levels reported are high compared with the present criteria for initiating anti-hypertensive treatment; this study was, however, started in 1990 pior to the results of three recent trials in elderly hypertensives. ${ }^{18-20}$

The study was too small to detect any differences between type of therapy and presence of orthostatic hypotension, but does suggest it can take many months for any effect of anti-hypertensive 
therapy on orthostatic hypotension to be abolished following treatment withdrawal.

In conclusion, withdrawal of anti-hypertensive therapy and institution of non-pharmacological treatment can over several months reduce the prevalence of orthostatic hypotension in elderly hypertensive patients.

\section{References}

1. Weinberger, M.H. Diuretics and their side effects, dilemma in the treatment of hypertension. Hypertens 1988, 11 (Suppl 11): 16-20.

2. Schatz, I.J. Orthostatic hypotension. 1. Functional and neurogenic causes. Arch Intern Med 1984, 144: 773-777.

3. Rosenthal, M.J. \& Naliboff, B. Postural hypotension: its meaning and management in the elderly. Geriatrics 1988, 43: $31-42$.

4. Rubenstein, L.Z. \& Robbins, A.S. Falls in the elderly: a clinical perspective. Geriatrics 1984, 39: 67-78.

5. Davis, B.R., Langford, H.G., Blaufox, M.D., Curb, D.J., Polk, B.F. \& Shulman, N.B. The association of postural changes in systolic blood pressure and mortality in persons with hypertension: the Hypertension Detection and Followup Program experience. Circulation 1987, 75: 340-346.

6. Burke, V., Beilin, L.J., German, R. et al. Postural fall in blood pressure in the elderly in relation to drug treatment and other lifestyle factors. $Q J \mathrm{Med}$ 1992, 304: 583-591.

7. Applegate, W.B., Davis, B.R., Black, H.R., Smith, W.M., Miller, S.T. \& Burlando, A.J. Prevalence of postural hypotension at baseline in the systolic hypertension in the elderly (SHEP) cohort. J Am Geriatr Soc 1991, 39: 1057-1064.

8. Caird, F.I., Andrews, G.R. \& Kennedy, R.D. Effect of posture on blood pressure in the elderly. Br Heart J 1973, 35: 527-530.

9. Alli, C., Avanzini, F., Bettelli, G. et al. Prevalence and variability of orthostatic hypotension in the elderly. Results of the 'Italian study on blood pressure in the elderly (SPAA)'. Eur Heart J 1992, 13, 178-182.

10. Ensrud, K.E., Nevitt, M.C., Yunis, C., Hulley, S.B., Grimm, R.H. \& Cummings, S.R. Postural hypotension and postural dizziness in elderly women. Arch Intern Med 1992, 152: 1058-1064.

11. Harris, T., Lipsitz, L.A., Kleinman, J.C. \& Cornoni-Huntley, J. Postural change in blood pressure associated with age and systolic blood pressure. J Gerontol 1991, 46: M159-163.

12. Rutan, G.H., Hermanson, B., Bild, D.E., Kittner, S.J., LaBaw, F. \& Tell, G.S. Orthostatic hypotension in older adults, The Cardiovascular Health Study. Hypertens 1992, 19: $508-519$.

13. Myers, M.G., Kearns, P.M., Kennedy, D.S. \& Fisher, R.H. Postural hypotension and diuretic therapy in the elderly. Can Med Assoc J 1978, 119: 581-585.

14. Vardon, S., Hill, N.E., Mehrotra, K.G., Mookherjee, S. \& Smulyan, H. Hemodynamic response to orthostatic stress in the elderly with systolic systemic hypertension before and after long-term thiazide therapy. Am J Cardiol 1993, 71: $582-586$.

15. Stern, N., Beahm, E., McGinty, D. et al. Dissociation of 24-hour catecholamine levels from blood pressure in older men. Hypertension 1985, 7: 1023-1029.

16. MacLennan, W.J., Hall, M.R.P. \& Tomothy, J.I. Postural hypotension in old age: is it a disorder of the nervous system or of blood vessels? Age Ageing 1980, 12: 25-32.

17. Lipsitz, L.A., Storch, H.A., Minaker, K.L. \& Rowe, J.W. Intraindividual variability in postural blood pressure in the elderly. Clin Sci 1985, 69: 3377-3381.

18. MRC Working Party. Medical Research Council trial of treatment of hypertension in older adults: principal results. Br Med J 1992, 304: 405-412.

19. SHEP Cooperative Research Group. Prevention of stroke by anti-hypertensive drug treatment in older persons with isolated systolic hypertension. JAMA 1991, 265: 3255-3264.

20. Dahlof, B., Linholm, L.H., Hannson, L., Schertsen, B., Ekbom, T. \& Wester, P. Morbidity and mortality in the Swedish trial in old patients with hypertension (STOPHypertension). Lancet 1991, 338: 1281-1285. 